\title{
Versatile 3D-Printed Micro-Reference Electrodes for Aqueous and Non-Aqueous Solutions
}

\author{
Fabian M. Schuett, Sven J. Zeller, Maximilian J. Eckl, Felix M. Matzik, Maren-Kathrin Heubach, \\ Tanja Geng, Johannes M. Hermann, Matthias Uhl, Ludwig A. Kibler,* Albert K. Engstfeld, * and \\ Timo Jacob*
}

\begin{abstract}
While numerous reference electrodes suitable for aqueous electrolytes exist, there is no well-defined standard for non-aqueous electrolytes. Furthermore, reference electrodes are often large and do not meet the size requirements for small cells. In this work, we present a simple method for fabricating stable 3D-printed micro-reference electrodes. The prints are made from polyvinylidene fluoride, which is chemically inert in strong acids, bases, and commonly used non-aqueous solvents. We chose six different reference systems based on $\mathrm{Ag}, \mathrm{Cu}, \mathrm{Zn}$, and $\mathrm{Na}$, including three aqueous and three nonaqueous systems to demonstrate the versatility of the approach. Subsequently, we conducted cyclic voltammetry experiments and measured the potential difference between the aqueous homemade reference electrodes and a commercial $\mathrm{Ag} / \mathrm{AgCl}$ electrode. For the non-aqueous reference electrodes, we chose the ferrocene redox couple as an internal standard. From these measurements, we deduced that this new class of microreference electrodes is leak-tight and shows a stable electrode potential.
\end{abstract}

\section{Introduction}

Precise reading and control of electrode potentials are of utmost importance for electrochemical measurements and devices. For electrochemical measurements conducted in

[*] F. M. Schuett, S. J. Zeller, M. J. Eckl, F. M. Matzik, M.-K. Heubach, T. Geng, J. M. Hermann, M. Uhl, Dr. L. A. Kibler, Dr. A. K. Engstfeld, Prof. Dr. T. Jacob

Institute of Electrochemistry, Ulm University

Albert-Einstein-Allee 47, 89081 Ulm (Germany)

E-mail: ludwig.kibler@uni-ulm.de albert.engstfeld@uni-ulm.de timo.jacob@uni-ulm.de

S. J. Zeller, Prof. Dr. T. Jacob

Helmholtz-Institute-Ulm (HIU), Electrochemical Energy Storage

Helmholtzstr. 11, 89081 Ulm (Germany)

S. J. Zeller, Prof. Dr. T. Jacob

Karlsruhe Institute of Technology (KIT)

P.O. Box 3640, 76021 Karlsruhe (Germany)

(2) Supporting information and the ORCID identification number(s) for

iD the the author(s) of this article can be found under: https://doi.org/10.1002/anie.202105871.

of (c) 2021 The Authors. Angewandte Chemie International Edition published by Wiley-VCH GmbH. This is an open access article under the terms of the Creative Commons Attribution Non-Commercial NoDerivs License, which permits use and distribution in any medium, provided the original work is properly cited, the use is noncommercial and no modifications or adaptations are made. a three-electrode set-up, consisting of a working electrode (WE), a counter electrode (CE), and a reference electrode (RE), a potentiostat typically controls the potential difference between the WE and the RE. ${ }^{[1,2]}$ REs are galvanic half-cells with a constant and reproducible electrode potential that can be achieved in the simplest case by immersing a pure metal into a solution containing its ions. ${ }^{[1]}$ Considering that the metal electrode is in thermodynamic equilibrium with the electrolyte, the half-cell is denoted according to the following example, where metallic $\mathrm{Cu}$ is immersed into an aqueous copper sulphate solution: $\mathrm{Cu}_{(\mathrm{s})} \mid \mathrm{CuSO}_{4(\mathrm{aq})}$. The single vertical bar denotes the phase boundary. ${ }^{[1,3]}$ Thermodynamic equilibrium is established when the electrochemical potential $\tilde{\mu}_{i}^{j}$ of any component $i$ crossing the phase boundary between two adjacent phases $j$ is identical, that is, for phases $\alpha$ and $\beta$ :

$\tilde{\mu}_{i}^{\alpha}=\tilde{\mu}_{i}^{\beta}$.

The electrochemical potential of component $I$ in a phase can be written as a sum of the chemical potential of the component and a contribution of electrostatic energy

$\tilde{\mu}_{i}^{\alpha}=\mu_{i}^{\alpha}+z_{i} F \phi^{\alpha}$,

where $\mu_{i}^{\alpha}$ is the chemical potential, $z_{i} F$ is the charge of one mole of component $i$, and $\phi^{\alpha}$ is the Galvani potential of the bulk phase $\alpha$. The electrode potential $E$ is defined as the reversible cell voltage of the (hypothetical) electrochemical cell consisting of the half-cell under study and the standard hydrogen electrode (SHE) in equilibrium with each other. Overall, $E$ is the difference in electrostatic potentials of the terminals with identical chemical nature in the absence of current flowing through the circuit (there is no net current after electrochemical equilibrium is established). This reversible cell voltage $E$ is related to the Gibbs free energy $\Delta G_{r}$ of the cell reaction with $z$ being the number of transferred electrons: $:^{[4-7]}$

$\Delta G_{r}=-z F E$.

In the case of more than two phases, as is the case for second-kind (or secondary) reference electrodes, the previously introduced nomenclature is applied analogously, for example, for a $\mathrm{Ag}$ wire in a $\mathrm{KCl}$ solution with a $\mathrm{AgCl}$ precipitate: $\mathrm{Ag}_{(\mathrm{s})}\left|\mathrm{AgCl}_{(\mathrm{s})}\right| \mathrm{KCl}_{(\mathrm{aq})}{ }^{[1]}$ In this case, thermodynamic equilibrium is established between the three phases. This implies that the electrode potential is a function of the 
activity of the common anion $A^{-}$in solution:

$$
\begin{aligned}
& \mathrm{M}_{(\mathrm{s})} \rightleftharpoons \mathrm{M}_{(\text {solv })}^{++}+z \mathrm{e}^{-} \\
& \mathrm{MA}_{(\mathrm{s})} \rightleftharpoons \mathrm{M}_{(\text {solv })}^{z+}+\mathrm{A}_{(\text {solv })}^{z-} \\
& E=E^{\circ}+\frac{R T}{z F} \ln \frac{a_{\mathrm{M}_{\text {(solv) }}^{z+}}^{z+}}{a_{\mathrm{M}_{(\mathrm{s})}}}=E^{\circ}+\frac{R T}{z F} \ln \frac{a_{\mathrm{MA}_{(\mathrm{s})}}}{a_{\mathrm{M}_{(\mathrm{s})}} a_{\mathrm{A}_{(\text {solv })}^{z-}}} \\
& \approx E^{\circ}-\frac{R T}{z F} \ln a_{\mathrm{A}_{\text {(solv) }}^{z-}}
\end{aligned}
$$

with $E$ being the electrode potential, $E^{\circ}$ the standard electrode potential at a pressure of 1 bar and constant absolute temperature $T, R$ the universal gas constant, $z$ the number of transferred electrons according to the reaction equation, $F$ the Faraday constant and $a_{\mathrm{A}_{\text {solvy }}^{-}}$the activity of the common anion. ${ }^{[3,8,9]}$ For example, for $\mathrm{Ag} / \mathrm{AgClv} g \mathrm{REs}$ employed in a chloride-containing electrolyte, the activity $a_{\mathrm{Cl}^{-}}$is crucial for the electrode potential. ${ }^{[8]}$ Thus, this RE system can be denoted as $\mathrm{Ag}_{(\mathrm{s})}\left|\mathrm{AgCl}_{(\mathrm{s})}\right| \mathrm{Cl}^{-}$(solv).

While many different types of second-kind REs are commercially available for aqueous electrolytes, these are often not suitable for other applications with small cell volumes or non-aqueous electrolytes. ${ }^{[10]}$ For miniature electrochemical cells, which are commonly used for measurements with costly and scarce ionic liquids (IL), usually, pseudo-REs or quasi-REs are employed. ${ }^{[11]}$ A similar problem arises for in situ scanning tunneling microscopy (STM) and in situ atomic force microscopy (AFM) measurements with aqueous and non-aqueous electrolytes, where geometrical constraints limit the application of commercial REs. Some pseudo-REs, such as the often-used Pt or Ag wires, can show quasi-stable electrode potentials under certain conditions. However, electrode potentials of pseudo-RE are usually ill-defined since thermodynamic equilibrium is not reached and thus the electrode potential can shift up to several hundred $\mathrm{mV}$. This can be caused, for example, by uncontrolled surface reactions, $\mathrm{pH}$ changes due to $\mathrm{OH}^{-}$or $\mathrm{H}^{+}$ formation, or the evolution of oxygen or other electrochemical active compounds, e.g., electrolyte decomposition products. ${ }^{[11-13]}$

In recent years, there have been several reports attempting to overcome these issues. One approach consists of coating the previously mentioned quasi-reference metal wire to generate a kind of pseudo-equilibrium. A typical example is the Ag wire pseudo-RE, which is coated with an insoluble salt such as $\mathrm{AgCl}^{[14-17]}$ For $\mathrm{Pt}$ wires, coatings consisting of poly (vinylferrocene) (PVFc) or poly ( $N$-ferrocenyl-methyl- $N$ allylimidazolium bromide) have been reported which use the $\mathrm{Fc} / \mathrm{Fc}^{+}$-couple as a reference. ${ }^{[11,18,19]}$ However, all of these electrodes suffer from insufficient chemical stability, i.e., are prone to dissolution in certain electrolytes or decompose in light or in contact with oxygen, which among other aspects, significantly lowers their lifetime. ${ }^{[12,20]}$ Another more recent approach is based on small REs made from an activated carbon/Teflon composite, explicitly designed for in situ STM studies. ${ }^{[10]}$ Such activated carbon electrodes are often referred to as "universal quasi-reference electrodes". They are considered as ideal polarizable REs, where a current flow is purely capacitive. ${ }^{[21,22]}$ It has been shown that these electrodes are stable in certain electrolytes (including ionic liquids). ${ }^{[23,24]}$ Nevertheless, their potential strongly depends on the particular electrolyte and is often only stable in a certain potential range. This is different from ideal non-polarizable electrodes where the electrode potential does not change upon charging the electrode via faradaic or, capacitive contributions, or both. $^{[12,20]}$

Overall, the task of finding a universal reference electrode, especially for ILs, is very complicated due to the unique chemical and physical properties of each system. ${ }^{[8]}$ As a rule of thumb, the chemical properties of the RE should be similar to those present in the electrochemical system in which it is employed. ${ }^{[2]}$ This aspect is of particular importance for studies related to metal deposition since the overpotential is by definition at $0 \mathrm{~V}$ for activities of unity. Hence, the design of an individual second-kind RE for every system under study would be an optimum solution to the problem. For example, in the case of metal deposition from an IL the ideal RE should be based on the to-be-deposited metal in the very same IL; stored in a saturated solution of the metal salt in the IL. For studying the pure IL, however, the RE should be stored in the pure IL.

In the context of designing a non-pseudo RE, Huber and Roling presented an $\mathrm{Ag} / \mathrm{Ag}^{+}$micro-RE for electrochemical measurements in miniature cells with ILs. ${ }^{[13]}$ Those microREs consist of a silica capillary with an outer diameter of only $350 \mu \mathrm{m}$, filled with $20-40 \mu \mathrm{L}$ of a $10 \mathrm{mM} \mathrm{Ag}$ salt solution. However, these micro-REs cannot be modified to create second-kind REs, since additional salt sediment does not fit in those capillaries. Other workgroups followed an approach where customizable REs were prepared from everyday laboratory supplies, as felt-tipped pens or micropipettes. ${ }^{[25-27]}$ A more recent approach demonstrates the preparation of customizable REs with 3D-printed housings. Key advantages of $3 \mathrm{D}$-printing are that prototypes can be produced more economically and faster than by other manufacturing methods. Additionally, it offers the flexibility to alter the shape of the RE to suit specific needs. ${ }^{[28]}$ However, the REs presented in that work are large and hence not suitable for applications in small cells. Besides, those REs are printed from acrylonitrile butadiene styrene (ABS) that is unstable in acidic electrolytes and similar to the approach of other groups, ${ }^{[29,30]}$ agar plugs are used to seal the bottom part, which is prone to leakage depending on pore size and temperature. ${ }^{[31]}$

Based on this novel design approach, we provide in this work simple step-by-step instructions for the fabrication of 3D-printed second-kind micro-REs, suitable for application in electrochemical cells with small electrolyte volumes $(\mu \mathrm{L}$ range). The micro-REs with a length of $\approx 40 \mathrm{~mm}$ and an outer diameter of $4 \mathrm{~mm}$ were 3D-printed from chemically resistant polyvinylidene fluoride (PVDF). So far, we could only find that PVDF is not stable in diglyme (bis(2-methoxyethyl)ether), which is used, for example, as an electrolyte in sodium-ion batteries. ${ }^{[32,33]}$ Leak tightness is achieved by sealing the electrodes with a magnesia stick. The dimensions of the micro-REs are sufficiently large that salt sediment can be added at the bottom, enabling the preparation of a secondkind micro-RE. Furthermore, the small size enables their use 
in electrochemical miniature cells, such as for in situ STM measurements. We also present non-aqueous Na-based micro-REs, which have not yet been reported to the best of our knowledge. The versatility of 3D-printing allows for designing customized REs for a wide range of electrochemical cells or problems. In total, the vast range of applications is demonstrated for six micro-REs; three aqueous and three nonaqueous. The stability of the electrode potentials and the related leak-tightness were tested by measuring the reversible cell voltage against a commercial $\mathrm{Ag} / \mathrm{AgCl}$-electrode, measurements with the ferrocene redox couple as internal standard, and by cyclic voltammetry (CV). Note that the price of a 3D-printed micro-RE housing in the described size is only a few cents and hence magnitudes cheaper than commercial micro-REs.

\section{Results and Discussion}

\section{Part I: Reference Electrode Fabrication and Assembly}

The general applicability of our approach is demonstrated for six micro-REs, three for aqueous and three for nonaqueous electrolytes:

$$
\begin{aligned}
& \mathrm{Ag}_{(\mathrm{s})}\left|\mathrm{AgCl}_{(\mathrm{s})}\right| \mathrm{Cl}_{(\mathrm{aq})}^{-} \rightarrow \mathrm{Ag} / \mathrm{AgCl} \\
& \mathrm{Ag}_{(\mathrm{s})}\left|\mathrm{Ag}_{2} \mathrm{SO}_{4(\mathrm{~s})}\right| \mathrm{SO}_{4(\mathrm{aq})}^{2-} \rightarrow \mathrm{Ag} / \mathrm{Ag}_{2} \mathrm{SO}_{4} \\
& \mathrm{Cu}_{(\mathrm{s})}\left|\mathrm{CuSO}_{4(\mathrm{~s})}\right| \mathrm{SO}_{4(\mathrm{aq})}^{2-} \rightarrow \mathrm{Cu} / \mathrm{CuSO}_{4} \\
& \mathrm{Zn}_{(\mathrm{s})}\left|\mathrm{Zn}(\mathrm{TFSI})_{2(\mathrm{~s})}\right| \mathrm{TFSI}^{-}{ }_{([\mathrm{MPPip}][\mathrm{TFSI}])} \rightarrow \mathrm{Zn} / \mathrm{Zn}(\mathrm{TFSI})_{2} \\
& \mathrm{Cu}_{(\mathrm{s})}\left|\mathrm{CuCl}_{2(\mathrm{ChCl}+\text { TFA) }}\right| \mathrm{Cl}^{-}{ }_{(\mathrm{ChCl}+\text { TFA) }} \rightarrow \mathrm{Cu} / \mathrm{CuCl}_{2} \\
& \mathrm{Na}_{(\mathrm{s})}\left|\mathrm{NaTFSI}_{(\mathrm{s})}\right| \text { TFSI }_{(\text {(MPPip][TFSI] })}^{-} \rightarrow \mathrm{Na} / \mathrm{NaTFSI}
\end{aligned}
$$

with [MPPip][TFSI] being the abbreviation for the IL $N$ methyl- $N$-propylpiperidinium bis(trifluoromethanesulfony1)imide, TFSI for the anion bis(trifluoromethanesulfonyl)imide, $\mathrm{ChCl}$ for choline chloride, and TFA for trifluoroacetamide. A detailed description of the pre-treatment of the chemicals employed in the following assembly instruction is provided in the experimental section (see Supporting Information). Especially the careful pre-treatment of the nonaqueous chemicals is crucial to obtain stable micro-REs.

The individual parts and illustrations for the following step-by-step instructions for the assembly of micro-REs are presented in Figure 1. Figure $1 \mathrm{a}$ shows the 3D-printing process and Figure $1 \mathrm{~b}$ depicts designs of REs for different cell geometries, demonstrating the versatility of this approach. A detailed description of the cell design, 3D printing parameters, and the process is provided in the experimental section. Before the assembly, the PVDF housing components were cleaned by storing the individual parts for 24 to $48 \mathrm{~h}$ in Caro's acid. Subsequently, the parts were six times boiled and rinsed in ultra-pure water and finally dried for two to three days in a furnace at $100^{\circ} \mathrm{C}$. All other parts (heat-shrink tubings, metal wires, and magnesia sticks) were thoroughly rinsed with isopropyl alcohol and water and afterwards boiled, rinsed, and dried in the same way as the PVDF parts.

The general RE assembly for a micro-RE, with a linear housing design, is depicted in Figure 1c. First, a wire (1) with a diameter of $1 \mathrm{~mm}$ is inserted into the 3D-printed PVFD lid (2), which forms the top part of a micro-RE (3). Depending

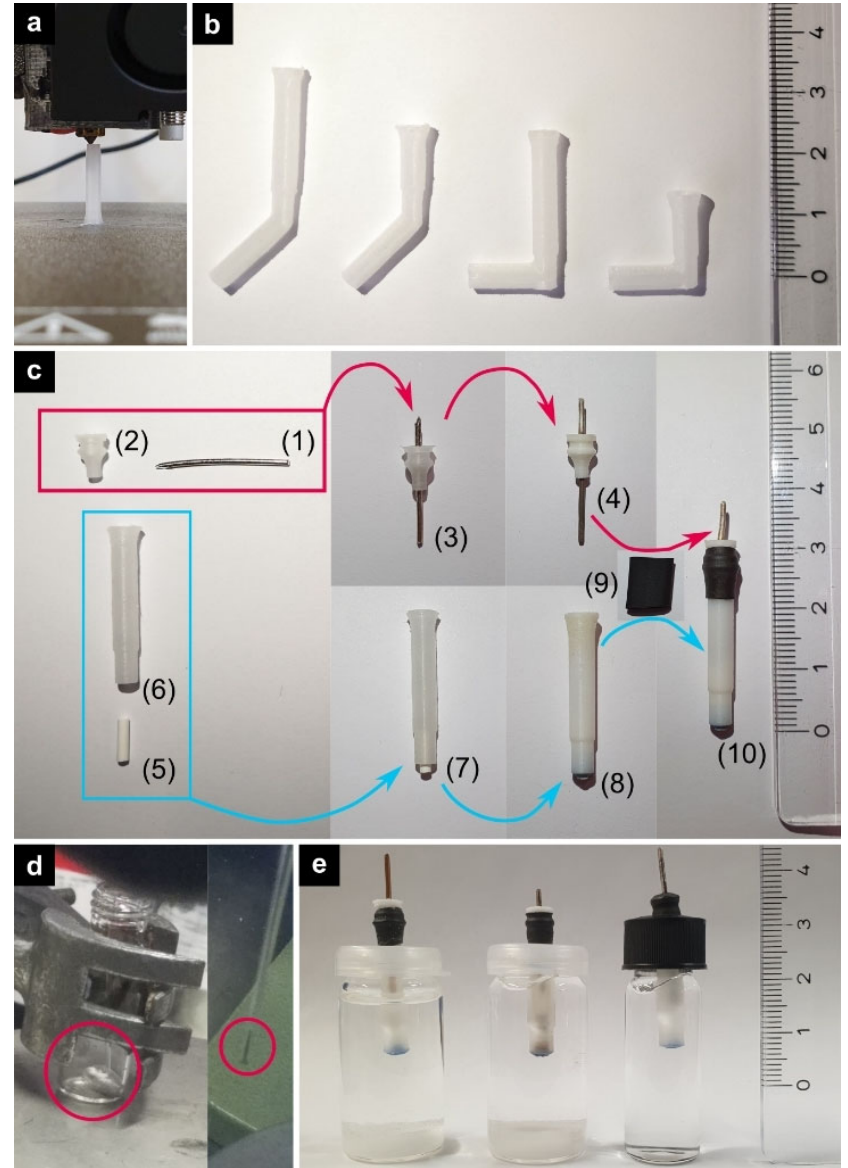

Figure 1. Individual parts and step-by-step procedure for the fabrication of micro-REs. a) Printing of the housing components. b) Selected designs of micro-RE housings, for different cell geometries. c) Assembly instruction of the individual parts for a linear micro-RE (see text for details). d) Fabrication of the inner sodium electrode for the $\mathrm{Na}$ / NaTFSI micro-RE. e) Final assembly of the micro-REs, shown for an aqueous $\mathrm{Cu} / \mathrm{CuSO}_{4}$ (left), $\mathrm{Ag} / \mathrm{Ag}_{2} \mathrm{SO}_{4}$ (middle), and $\mathrm{Ag} / \mathrm{AgCl}$ (right) micro-RE; stored in saturated $\mathrm{K}_{2} \mathrm{SO}_{4}$ for the sulphate-based REs and in $1 \mathrm{M} \mathrm{KCl}$ solution for the $\mathrm{Ag} / \mathrm{AgCl} \mathrm{RE}$.

on the type of micro-RE the metal wire is treated in different ways, indicated by steps (3) to (4). Details about this step are provided further below. For the bottom part, a magnesia stick (5) with a diameter and approximate length of $2 \mathrm{~mm}$ and $5 \mathrm{~mm}$, respectively, is inserted into the $3 \mathrm{D}$ printed PVDF housing (6). Subsequently, a chemical resistant resin is employed (7) to attach both parts, which forms the bottom part of the RE (8). After the separate preparation of the top (4) and the bottom part (8) (see further below), the micro-RE is finally assembled. Therefore, the top part (4) is inserted into the bottom part (8) and sealed with heat-shrink tubing (9), thus generating the final fabricated micro-RE (10).

In the following, we provide detailed preparation procedures for the top (4) and the bottom (8) parts of the three aqueous and three non-aqueous micro-REs before the final assembly. Note that for the non-aqueous micro-REs the preparation, as well as the final assembly, is conducted in a glovebox under an inert gas atmosphere. 
$\mathrm{Ag} / \mathrm{AgCl}$ : The bottom part (8) is filled with a solution of $1 \mathrm{M} \mathrm{KCl}$. Note that concentrated chloride solutions should be avoided since the usually poorly soluble $\mathrm{AgCl}$ becomes well soluble as $\left[\mathrm{AgCl}_{2}\right]^{-}$complex in solutions with high chloride content. ${ }^{[34]}$ The Ag wire from the top part (3) is electrochemically chlorinated for $60 \mathrm{~s}$ in $1 \mathrm{M} \mathrm{HCl}$ at $5 \mathrm{~V}$ vs. a carbon rod to form part (4).

$\mathrm{Ag} / \mathrm{Ag}_{2} \mathrm{SO}_{4}$ : A saturated $\mathrm{K}_{2} \mathrm{SO}_{4}$ solution with precipitate is filled into the bottom part (8). The Ag wire from the top part (3) is electrochemically sulphated for $60 \mathrm{~s}$ in $0.1 \mathrm{M}$ $\mathrm{H}_{2} \mathrm{SO}_{4}$ at $5 \mathrm{~V}$ vs. a carbon rod to form part (4).

$\mathrm{Cu} / \mathrm{CuSO}_{4}$ : Some crystals of $\mathrm{K}_{2} \mathrm{SO}_{4}$ are added to the bottom part (8). Subsequently, the part is filled with a concentrated $\mathrm{K}_{2} \mathrm{SO}_{4}$ solution. The $\mathrm{Cu}$ wire from the top part (3) is electrochemically sulphated for $60 \mathrm{~s}$ in $0.1 \mathrm{M}$ $\mathrm{H}_{2} \mathrm{SO}_{4}$ at $5 \mathrm{~V}$ vs. a carbon rod to form part (4).

$\mathrm{Zn} / \mathrm{Zn}(\mathrm{TFSI})_{2}$ : In the glovebox, some grains of $\mathrm{Zn}(\mathrm{TFSI})_{2}$ are added to the bottom part (8). Subsequently, the part is filled with [MPPip][TFSI] saturated with $\mathrm{Zn}^{2+}$. The $\mathrm{Zn}$ wire from the top part (3) is mechanically polished to remove the native oxide film to form part (4).

$\mathrm{Cu} / \mathrm{CuCl}_{2}$ : In the glovebox, the bottom part (8) is filled with a $0.1 \mathrm{M} \mathrm{CuCl}_{2}$ solution in a 1:2.25 mixture of $\mathrm{ChCl}$ with TFA. Note that a $0.1 \mathrm{M} \mathrm{CuCl}_{2}$ solution was chosen due to the high solubility of metal salts and oxides (until solidification of the mixture) in deep eutectic solvents (DES). ${ }^{[35,36]}$ The $\mathrm{Cu}$ wire from the top part (3) is mechanically polished to remove any native oxides to form part (4).

$\mathrm{Na}$ /NaTFSI: In the glovebox, some grains of NaTFSI are added to the bottom part (8). Subsequently, the part is filled with $\mathrm{Na}^{+}$saturated [MPPip][TFSI]. Note that for this micro-RE the assembly of the top part (3) is carried out with a $\mathrm{Cu}$ wire of only $0.5 \mathrm{~mm}$ diameter. $\mathrm{Na}$ metal is liquified in a glass vial on a heating plate at ca. $110-120^{\circ} \mathrm{C}$. The liquid $\mathrm{Na}$ is sucked up by a glass pipette until the $\mathrm{Na}$ column in the tip of the pipette reaches a height of $\approx 5$ $10 \mathrm{~mm}$ (see Figure $1 \mathrm{~d}$ ). After cooling down, the Na-filled tip of the pipette is carefully broken off. Subsequently, the $\mathrm{Cu}$ wire of the top part (3) is squeezed into the glass encapsulated $\mathrm{Na}$, until the $\mathrm{Cu}$ wire is completely immersed and the 3D-printed PVDF lid (2) touches the glass pipette, thus forming part (4).

After the assembly, the final micro-REs (10) were stored halfway immersed in a salt solution matching their inner electrolyte, as shown in Figure $1 \mathrm{e}$ for aqueous $\mathrm{Cu} / \mathrm{CuSO}_{4}, \mathrm{Ag}$ / $\mathrm{Ag}_{2} \mathrm{SO}_{4}$, and $\mathrm{Ag} / \mathrm{AgCl}$ micro-REs.

\section{Part II: Reference Electrode Characterization}

Depending on the electrolyte conditions (aqueous or nonaqueous), the leak-tightness and the stability of the potential of the micro-REs were determined by different experimental approaches.

Focusing on the aqueous micro-REs, we first determined both aspects by studying the electrochemical properties of $\mathrm{Pt}$ poly-oriented single crystals (POSC) in $\mathrm{H}_{2} \mathrm{SO}_{4}$ in a conven- tional electrochemical cell (see experimental part in the SI for details). Pt POSCs are ideal model systems since their surface structural properties are well-defined and can be prepared reproducibly via the flame fusion method. ${ }^{[37-39]}$ Furthermore, the electrochemical properties of polycrystalline Pt electrodes in $\mathrm{H}_{2} \mathrm{SO}_{4}$ are well described in the literature, ${ }^{[40-44]}$ and $\mathrm{Pt}$ electrodes are sensitive to contaminations, for example, chloride ions, eventually leaking out of the reference electrode. ${ }^{[45]}$ These aspects combined make Pt POSCs an ideal model system for the characterization of the home-made micro-REs.

Figure 2 a shows the voltammograms of a $\mathrm{Pt}$ POSC electrode recorded in $0.1 \mathrm{M} \mathrm{H}_{2} \mathrm{SO}_{4}$ at a scan rate of $50 \mathrm{mV} \mathrm{s}^{-1}$ with the different home-made aqueous micro-REs, that is, $\mathrm{Ag} / \mathrm{AgCl}$ in $1 \mathrm{M} \mathrm{KCl}$ (purple), $\mathrm{Ag} / \mathrm{AgSO}_{4}$ in saturated $\mathrm{K}_{2} \mathrm{SO}_{4}$ (green), and $\mathrm{Cu} / \mathrm{CuSO}_{4}$ in saturated $\mathrm{K}_{2} \mathrm{SO}_{4}$ (orange). The voltammogram obtained with a commercial $\mathrm{Ag} / \mathrm{AgCl} \mathrm{RE}$ is shown in black for comparison. In Figure $2 b$, the same data is plotted on the standard hydrogen electrode (SHE) scale. The shift of the potential for the different reference electrodes to the SHE scale is shown in Table 1. It is apparent that the voltammograms recorded with the home-made micro-REs are similar in quality to those obtained with the commercial
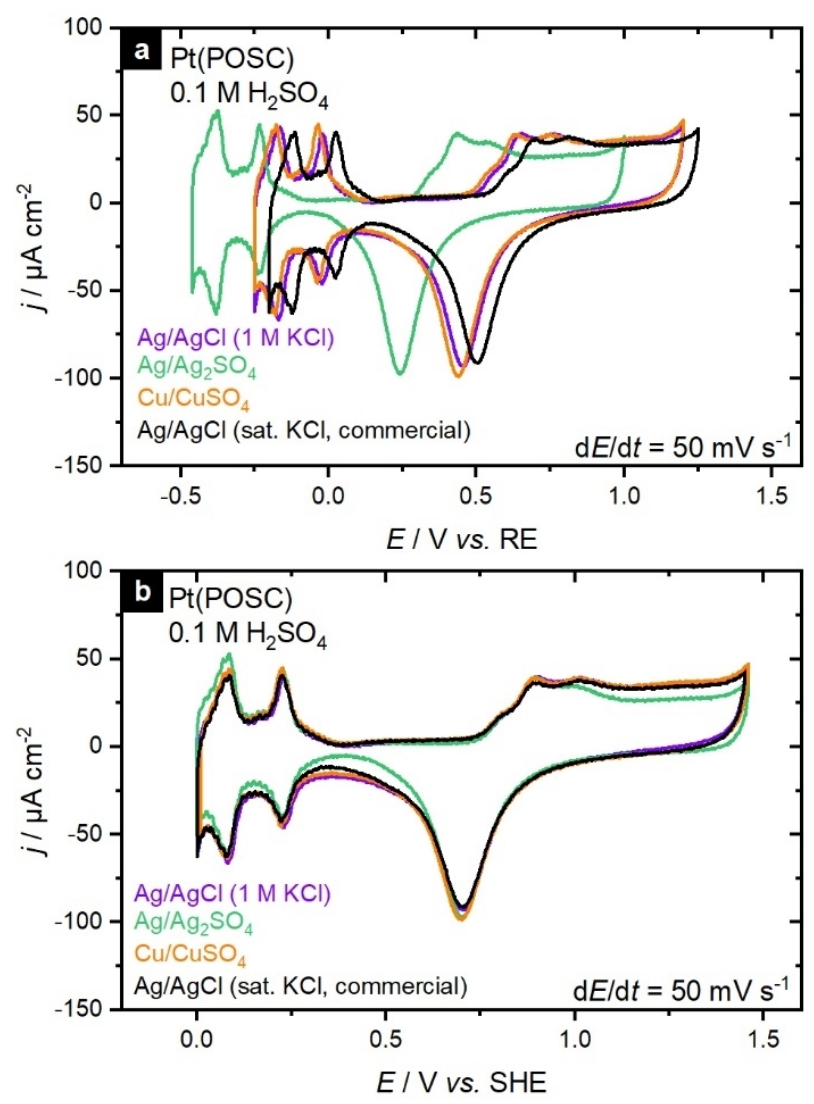

Figure 2. Cyclic voltammograms of a Pt POSC recorded at $50 \mathrm{mVs}^{-1}$ in $0.1 \mathrm{M} \mathrm{H}_{2} \mathrm{SO}_{4}$. Measurements were performed with the home-made aqueous micro-REs (colored curves) and a commercial $\mathrm{Ag} / \mathrm{AgCl} \mathrm{RE}$ (black curve) for comparison. The home-made $\mathrm{Ag} / \mathrm{AgCl}, \mathrm{Ag} / \mathrm{Ag}_{2} \mathrm{SO}_{4}$, and $\mathrm{Cu} / \mathrm{CuSO}_{4}$ micro-REs are depicted in purple, green, and orange, respectively. a) Voltammograms plotted vs. the respective reference electrode potential. b) The same curves plotted on the SHE scale. 
Table 1: Potential E vs. SHE at $298 \mathrm{~K}$ and temperature dependent potential shift $\mathrm{dE} / \mathrm{dT}$ of the home-made aqueous micro-REs.

\begin{tabular}{lll}
\hline $\mathrm{RE}$ & $E[\mathrm{mV}]$ vs. SHE & $\mathrm{d} E / \mathrm{d} T$ in $\mathrm{mVK}^{-1}$ \\
\hline $\mathrm{Ag} / \mathrm{AgCl}(1 \mathrm{M} \mathrm{KCl})$ & 240 & $-0.76 \pm 0.13$ \\
$\mathrm{Cu} / \mathrm{CuSO}$ & & $0.313 \pm 0.003$ \\
$\mathrm{Ag} / \mathrm{Ag}_{2} \mathrm{SO}_{4}$ & 268 & $2.8 \pm 0.3$ \\
\hline
\end{tabular}

$\mathrm{Ag} / \mathrm{AgCl} \mathrm{RE}$. The voltammogram recorded with the $\mathrm{Ag} /$ $\mathrm{Ag}_{2} \mathrm{SO}_{4}$ micro-RE (Figure 3, green curves) deviates slightly. A reason is that the calculated current densities can slightly vary in each measurement since the height of the electrolytic meniscus on the POSC (or also connecting wire) is difficult to control. Especially the undefined crystallographic orientation of the wire can lead to slightly different current densities at different potentials. More importantly, however, is that the position of the peaks does not change, which would be expected from an unstable RE. Besides the well-known voltametric features, no additional oxidation or reduction peaks from leaking metal ions from the micro-RE could be detected. To further check for leakage, directly after the CV experiments, the potential of the working electrode was set to $-100 \mathrm{mV}$ (relative to the particular reference system) for 60 minutes, to deposit electrochemically and thus accumulate all ions that would leak from the micro-RE on the WE. After this waiting time, further voltammograms were recorded, which still did not reveal additional redox peaks of metal ions or chloride contamination. Possible contamination by chloride is demonstrated in Figure S1 and is shown elsewhere. ${ }^{[45-49]}$ Similar experiments were subsequently performed in an electrochemical miniature cell, which is usually employed for non-aqueous measurements (see Figure 4 and further below). In this set-up, the RE is close to the WE $(\approx 1.8 \mathrm{~mm})$,

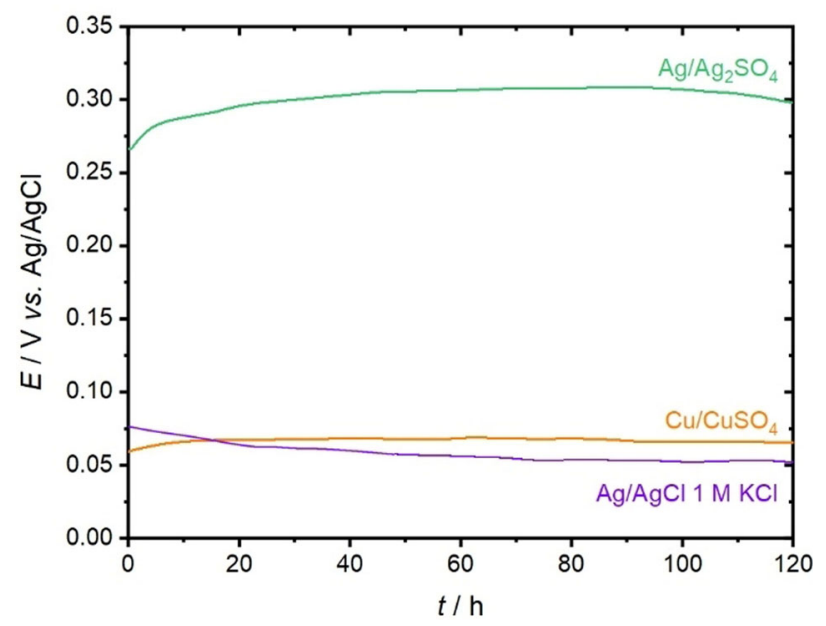

Figure 3. Time dependence of the cell voltage $E$ for the electrochemical cell consisting of the aqueous home-made micro-REs and a commercial $\mathrm{Ag} / \mathrm{AgCl} \mathrm{RE}$. The curve of the $\mathrm{Ag} / \mathrm{AgCl}$ micro- $\mathrm{RE}$ was measured in $1 \mathrm{M} \mathrm{HCl}$ and is plotted in purple, the curves of the $\mathrm{Ag} / \mathrm{Ag}_{2} \mathrm{SO}_{4}$, and $\mathrm{Cu} / \mathrm{CuSO}_{4}$ micro-REs were measured in $0.1 \mathrm{M} \mathrm{H}_{2} \mathrm{SO}_{4}$ and are plotted in green, and orange. While the $\mathrm{Ag} / \mathrm{AgCl}$ and $\mathrm{Cu} / \mathrm{CuSO}_{4}$ electrodes were measured at $298 \mathrm{~K}$, due to lower stability at elevated temperature the potential of the $\mathrm{Ag} / \mathrm{Ag}_{2} \mathrm{SO}_{4}$ electrode was measured at $296 \mathrm{~K}$. The potential shift over time $d E / d t$ is for all REs smaller than $1.5 \mathrm{mVh}^{-1}$.
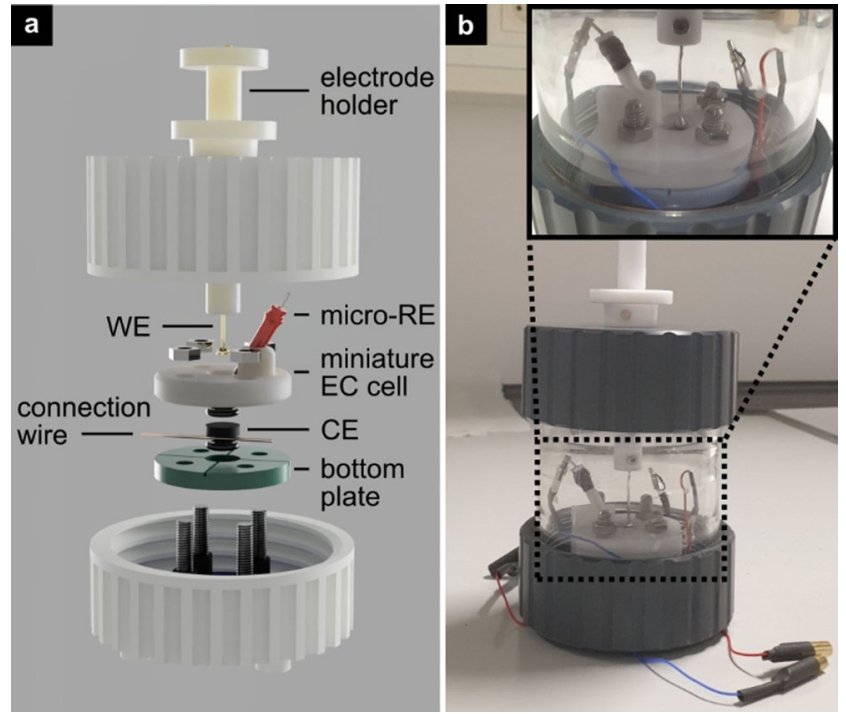

Figure 4. Electrochemical miniature cell: a) exploded-view drawing of the miniature cell set-up used for the measurements of the micro-REs. The micro-RE is highlighted in red. The WE is dipped from the top. As CE a graphite disc is used. b) Photograph of the assembled cell. The inset shows a magnification of the 3D-printed electrochemical miniature cell with a custom insertion slot for the micro-RE.

which allows for instant detection of leaking metal ions from the RE. Those experiments did not reveal any additional peaks caused by metal deposition as demonstrated in Figure S2.

The stability of the potential of the micro-REs becomes more apparent from Figure 3, which shows the temporal evolution of the potential $E$ for the electrochemical cell consisting of the aqueous home-made micro-REs and a commercial $\mathrm{Ag} / \mathrm{AgCl} \mathrm{RE}$ recorded over 120 hours. During these measurements, a thermostat was used to control the temperature of the electrolyte. These measurements were performed in $1 \mathrm{M} \mathrm{HCl}$ for the $\mathrm{Ag} / \mathrm{AgCl}$ micro-RE and in $0.1 \mathrm{M} \mathrm{H}_{2} \mathrm{SO}_{4}$ for the $\mathrm{Ag} / \mathrm{Ag}_{2} \mathrm{SO}_{4}$ and $\mathrm{Cu} / \mathrm{CuSO}_{4}$ micro-REs. At the beginning of the measurements, the potential of the REs drifts slightly, which indicates that all REs need to adapt to the electrolyte, concentration, and temperature. In the following hours, the equilibrium potentials of the REs are relatively stable $\left(\mathrm{d} E / \mathrm{d} t<1.5 \mathrm{mVh}^{-1}\right)$. Note that the fluctuations and shifts can also be caused by the commercial RE and that shifts in opposite directions on each electrode lead to a larger change in $E$. The impact of temperature changes on the stability of the micro-REs is described in Figure S3. Increasing the temperature leads to a linear shift of the potential $E$. The temperature derivative of the potential $(\mathrm{d} E / \mathrm{d} T)$ is included in Table 1.

As discussed above and elsewhere, ${ }^{[2]}$ to avoid significant fluctuations upon immersion in the electrolyte, every RE should be prepared for a specific system and stored in the corresponding electrolyte. Accordingly, the observed initial fluctuation of $\Delta E$ for the $\mathrm{Ag} / \mathrm{Ag}_{2} \mathrm{SO}_{4}$ and $\mathrm{Cu} / \mathrm{CuSO} \mathrm{S}_{4}$ microREs, measured in $0.1 \mathrm{M} \mathrm{H}_{2} \mathrm{SO}_{4}$, could also very likely be caused by fluctuations of the equilibrium potential of the commercial $\mathrm{Ag} / \mathrm{AgCl} \mathrm{RE}$, which is not the most suitable electrode in $\mathrm{SO}_{4}{ }^{2-}$ containing electrolytes. 
For the measurements in non-aqueous electrolytes, the leak tightness and stability of the potential were investigated in an electrochemical miniature cell, illustrated and pictured in Figure 4. Such cells are commonly used when working with expensive and scarce non-aqueous electrolytes, for example, DES and especially ILs. The small cell volume (200 to $400 \mu \mathrm{L})$ and the proximity of the RE to the WE $(1.8 \mathrm{~mm})$, allow for the instant detection of leaking ions from the REs, by the emergence of additional redox peaks in the voltammogram. All experiments with the non-aqueous micro-REs were performed under an inert gas atmosphere in a glove box. In contrast to the previously shown benchmark measurements performed with the aqueous micro-REs on a Pt POSC, there exist no equally well-established standards for non-aqueous systems. Hence, we suggest the following approach, which yielded reproducible results. As WE a $\mathrm{Au}(111)$ single crystal electrode was used, which offers a clean and atomically welldefined surface, is stable to oxidation, and thus often used for fundamental studies of non-aqueous systems. ${ }^{[14,50-52]}$ Most importantly, however, it is far less catalytically reactive than $\mathrm{Pt}$, which can cause disintegration of the non-aqueous electrolytes. As solvent, we used acetonitrile (AcN) combined with tetrabutylammonium hexafluorophosphate $\left(\mathrm{TBAPF}_{6}\right)$ as conductive salt, which is widely used in the non-aqueous research community. Also, this electrolyte does hardly show any distinctive features in the $\mathrm{CV}$ of $\mathrm{Au}(111)$, hence allows for instant detection of leaking metal ions from the micro-REs. Finally, we added ferrocene, $\mathrm{Fe}(\mathrm{Cp})_{2}$, as an internal reference standard, which is also commonly used for non-aqueous systems. ${ }^{[53-56]}$

The leak-tightness of the REs was tested by CV measurements of the $\mathrm{Au}(111)$ electrode for one hour in $400 \mu \mathrm{L}$ of $0.1 \mathrm{M} \mathrm{TBAPF}_{6}$ in $\mathrm{AcN}$ in the miniature electrochemical cell. In this time no additional peaks emerged. After this experiment, $10 \mu \mathrm{L} \mathrm{AcN} \mathrm{saturated} \mathrm{with} \mathrm{Fe}(\mathrm{Cp})_{2}$ was added to the electrolyte and voltammograms of the $\mathrm{Au}(111)$ electrode were recorded at $50 \mathrm{mV} \mathrm{s}^{-1}$ for another two hours to confirm the stability of the REs in Figure 5 a (Na/NaTFSI in grey, Zn/ $\mathrm{Zn}(\mathrm{TFSI})_{2}$ in blue, and $\mathrm{Cu} / \mathrm{CuCl}_{2}$ in brown). The shift of the potential for the different reference electrodes compared to $\mathrm{Fe}(\mathrm{Cp})_{2}$ is summarized in Table 2. Slight changes in the voltammograms are only observed within the first 10 minutes of the measurement. Longer measurements were not possible, due to the slow evaporation of the electrolyte. In the cyclic voltammograms virtually no change of the anodic and cathodic peak potential is observable. The slight change of the peak current density to smaller values, mainly observed in the voltammogram obtained with the $\mathrm{Zn} / \mathrm{Zn}(\mathrm{TFSI})_{2}$ micro$\mathrm{RE}$ and nearly solely for the anodic peak, could be assigned to slow oxidation of $\mathrm{Fe}(\mathrm{Cp})_{2}$ with residual oxygen in the glovebox. A similar effect was observed in previous studies using $\mathrm{K}_{4} \mathrm{Fe}(\mathrm{CN})_{6}$ as an internal standard. ${ }^{[27]}$

To highlight the stability of the non-aqueous home-made micro-REs, Figure $5 \mathrm{~b}$ depicts the temporal evolution of the anodic and cathodic peak potential maxima of the $\mathrm{Fe}(\mathrm{Cp})_{2}$ redox couple deduced from the voltammograms shown in Figure $5 \mathrm{a}$. For the sake of clarity, only the values from one cycle recorded every 20 minutes were plotted. Corresponding half-wave potential $E_{1 / 2}$ are shown in a rescaled graph of
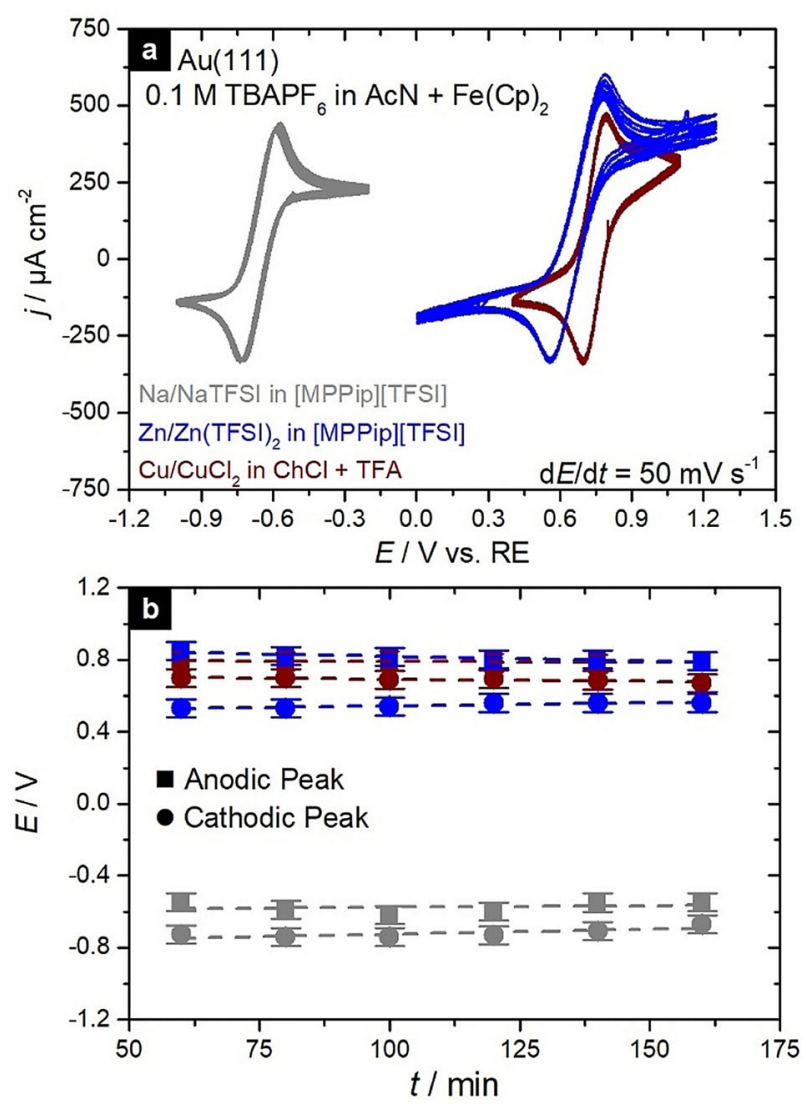

Figure 5. Cyclic voltammograms of an $\mathrm{Au}(111)$ single crystal recorded in a mixture of $0.1 \mathrm{M} \mathrm{TBAPF}_{6}$ in $\mathrm{AcN}$ with $\mathrm{Fe}(\mathrm{CP})_{2}$ at a scan rate of $50 \mathrm{mVs}^{-1}$. Measurements were conducted with the home-made microREs $\mathrm{Na} / \mathrm{NaTFSI}, \mathrm{Zn} / \mathrm{Zn}(\mathrm{TFSI})_{2}$, and $\mathrm{Cu} / \mathrm{CuCl}_{2}$ shown in grey, blue and brown, respectively. a) Cyclic voltammograms after addition of $\mathrm{Fe}(\mathrm{Cp})_{2}$ plotted against their relative potential. b) Anodic and cathodic peak maxima deduced from the curves shown in (a). For the sake of clarity, only the values from one cycle every 20 minutes were plotted.

Table 2: Potential $E$ vs. $\mathrm{Fe}(\mathrm{Cp})_{2}$ of the non-aqueous home-made aqueous micro-REs.

\begin{tabular}{ll}
\hline $\mathrm{RE}$ & $E / \mathrm{V}$ vs. Fe $(\mathrm{Cp})_{2}$ \\
\hline $\mathrm{Na} / \mathrm{NaTFSI}$ & 0.61 \\
$\mathrm{Zn} / \mathrm{Zn}(\mathrm{TFSI})_{2}$ & -0.68 \\
$\mathrm{Cu} / \mathrm{CuCl}{ }_{2}$ & -0.73 \\
\hline
\end{tabular}

Figure $5 \mathrm{~b}$ in Figure $\mathrm{S} 4$. The data indicates that the shift in potential is minimal during the measurement time of three hours for all three non-aqueous REs $\left(\mathrm{d} E / \mathrm{d} t<23 \mathrm{mVh}^{-1}\right)$. For comparison, on a similar time scale wire quasi-RE, which are often used under non-aqueous conditions, could shift several hundred $\mathrm{mV}$. To assess the stability of the potential over longer periods, repeated measurements have been performed with the same micro-REs showing a stable potential within the incertitude of the measurement during the time of a month. 


\section{Conclusion}

In this work, we presented a simple and versatile approach for the fabrication of tunable micro-REs for usage in electrochemical miniature cells and other applications. We explored three aqueous and three non-aqueous micro-REs based on $\mathrm{Ag}, \mathrm{Cu}, \mathrm{Zn}$, and $\mathrm{Na}$. For the aqueous micro-RE, the leak tightness and the temporal stability of the potential were demonstrated with voltammograms of a Pt POSC in acid solutions and by measuring the reversible cell voltage against a commercial $\mathrm{Ag} / \mathrm{AgCl}$-electrode. In the case of the nonaqueous micro-REs, the leak tightness and stability of the potential were demonstrated with voltammograms of Au(111) in $0.1 \mathrm{M} \mathrm{TBAPF} 6$ in $\mathrm{AcN}+\mathrm{Fe}(\mathrm{Cp})_{2}$. The PVDF material used for $3 \mathrm{D}$-printing of the RE housing is chemically stable in strong acids, bases, and even a broad range of commonly used non-aqueous liquids and solutions, e.g., ionic liquids, deep eutectic solvents, AcN, etc. This makes these REs highly versatile and easy to clean, for example in permanganate solutions or Caro's acid. So far, we could only find PVDF to be unstable in diglyme. With printing costs of the housing of only a few cents, the home-made micro-REs are magnitudes cheaper than commercially available (micro)REs.

\section{Acknowledgements}

We gratefully acknowledge the technical support of Jonas Geißel and Willi Kogler (workshop glass blowing and mechanics, Ulm University) in assisting in the design and manufacturing of the housing components of the electrochemical miniature cell (glass body and screw-tops). This research was funded by the Deutsche Forschungsgemeinschaft (DFG, German Research Foundation) under Germany's Excellence Strategy-EXC 2154-Project number 390874152 , as well as the Sonderforschungsbereiche (collaborative research centres) SFB-1316 and TRR-234. Open access funding enabled and organized by Projekt DEAL.

\section{Conflict of Interest}

The authors declare no conflict of interest.

Keywords: 3D-printing - cyclic voltammetry - electrochemistry . micro-reference electrodes - sodium reference electrode

[1] G. Inzelt in Handbook of Reference Electrodes, Springer Berlin Heidelberg, Berlin, 2013, pp. 1-24.

[2] D. Pletcher, R. Greff, R. Peat, L. M. Peter, J. Robinson, Instrumental Methods in Electrochemistry, Elsevier, 2010, pp. 356-387.

[3] Quantities, Units and Symbols in Physical Chemistry (Eds.: E. R. Cohen, T. Cvitas, J. G. Frey, B. Holström, K. Kuchitsu, R. Marquardt, I. Mills, F. Pavese, M. Quack, J. Stohner, et al.), Royal Society Of Chemistry, Cambridge, 2007.

[4] G. Wedler, H.-J. Freund, Lehr- und Arbeitsbuch Physikalische Chemie, Wiley-VCH, Weinheim, 2019, pp. 285-311.
[5] R. Seeber, C. Zanardi, G. Inzelt, ChemTexts 2015, 1, 18.

[6] V. S. Bagotsky, Fundamentals of electrochemistry, Wiley, Hoboken, 2006, pp. 19-31.

[7] I. N. Levine, Physics and Chemistry, McGraw-Hill, New York, 2009, pp. 395-441.

[8] A. I. Bhatt, G. A. Snook, Handbook of Reference Electrodes, Springer Berlin Heidelberg, Berlin, 2013, pp. 189-227.

[9] C. A. Vincent, J. Chem. Educ. 1970, 47, 365.

[10] A. Auer, J. Kunze-Liebhäuser, Electrochem. Commun. 2019, 98 , $15-18$.

[11] K. Izutsu, Handbook of Reference Electrodes, Springer Berlin Heidelberg, Berlin, 2013, pp. 145-187.

[12] G. Inzelt, Handbook of Reference Electrodes, Springer Berlin Heidelberg, Berlin, 2013, pp. 331-332.

[13] B. Huber, B. Roling, Electrochim. Acta 2011, 56, 6569-6572.

[14] M. Gnahm, T. Pajkossy, D. M. Kolb, Electrochim. Acta 2010, 55, $6212-6217$.

[15] M. Gnahm, C. Müller, R. Répánszki, T. Pajkossy, D. M. Kolb, Phys. Chem. Chem. Phys. 2011, 13, 11627.

[16] C. Müller, S. Vesztergom, T. Pajkossy, T. Jacob, J. Electroanal. Chem. 2015, 737, 218-225.

[17] M. Gnahm, C. Berger, M. Arkhipova, H. Kunkel, T. Pajkossy, G. Maas, D. M. Kolb, Phys. Chem. Chem. Phys. 2012, 14, 10647.

[18] P. J. Peerce, A. J. Bard, J. Electroanal. Chem. 1980, 108, 121-125.

[19] T. N. P. Truong, H. Randriamahazaka, J. Ghilane, Electrochem. Commun. 2016, 73, 5-9.

[20] Y. Z. Su, Y. C. Fu, Y. M. Wei, J. W. Yan, B. W. Mao, ChemPhysChem 2010, 11, 2764-2778.

[21] C. L. Wirth, R. M. Rock, P. J. Sides, D. C. Prieve, Langmuir 2011 , 27, $9781-9791$.

[22] P. W. Ruch, D. Cericola, M. Hahn, R. Kötz, A. Wokaun, J. Electroanal. Chem. 2009, 636, 128-131.

[23] D. Weingarth, A. Foelske-Schmitz, A. Wokaun, R. Kötz, Electrochem. Commun. 2012, 18, 116-118.

[24] A. Auer, X. Ding, A. S. Bandarenka, J. Kunze-Liebhäuser, J. Phys. Chem. C 2021, 125, 5020-5028.

[25] R. C. Massé, J. B. Gerken, J. Chem. Educ. 2015, 92, 110-115.

[26] S. N. Inamdar, M. A. Bhat, S. K. Haram, J. Chem. Educ. 2009, 86, 355.

[27] M. Duran-Chaves, J. Sanabria-Chinchilla, J. Chem. Educ. 2020, 97, $1208-1212$.

[28] B. Schmidt, D. King, J. Kariuki, J. Chem. Educ. 2018, 95, 20762080.

[29] A. W. Hassel, K. Fushimi, M. Seo, Electrochem. Commun. 1999, $1,180-183$.

[30] U. Hasse, F. Scholz, J. Solid State Electrochem. 2006, 10, $380-$ 382.

[31] J. Narayanan, J. Xiong, X. Liu, J. Phys. Conf. Ser. 2006, 28, $83-$ 86.

[32] K. Westman, R. Dugas, P. Jankowski, W. Wieczorek, G. Gachot, M. Morcrette, E. Irisarri, A. Ponrouch, M. R. Palacín, J.-M. Tarascon, et al., ACS Appl. Energy Mater. 2018, 1, 2671-2680.

[33] K. Gotoh, H. Maruyama, T. Miyatou, M. Mizuno, K. Urita, H. Ishida, J. Phys. Chem. C 2016, 120, 28152-28156.

[34] G. S. Forbes, J. Am. Chem. Soc. 1911, 33, 1937-1946.

[35] A. P. Abbott, G. Capper, D. L. Davies, K. J. McKenzie, S. U. Obi, J. Chem. Eng. Data 2006, 51, 1280-1282.

[36] E. L. Smith, A. P. Abbott, K. S. Ryder, Chem. Rev. 2014, 114, $11060-11082$

[37] N. Arulmozhi, G. Jerkiewicz, Electrocatalysis 2016, 7, 507-518.

[38] N. Arulmozhi, G. Jerkiewicz, Electrocatalysis 2017, 8, 399-413.

[39] N. Arulmozhi, D. Esau, J. van Drunen, G. Jerkiewicz, Electrocatalysis 2018, 9, 113-123.

[40] V. Climent, J. M. Feliu, Encyclopedia of Interfacial Chemistry, Elsevier, Amsterdam, 2018, pp. 48-74.

[41] B. Łosiewicz, R. Jurczakowski, A. Lasia, Electrochim. Acta 2012 , 80, 292-301. 
[42] P. Wongbua-ngam, W. Veerasai, P. Wilairat, O.-U. Kheowan, Int. J. Hydrogen Energy 2019, 44, 12108-12117.

[43] V. P. Santos, G. A. Camara, Results in Surfaces and Interfaces 2021, 3, 100006.

[44] D. R. Lowde, J. O. Williams, B. D. McNicol, Appl. Surf. Sci. 1978, $1,215-240$.

[45] S. Geiger, S. Cherevko, K. J. J. Mayrhofer, Electrochim. Acta 2015, 179, 24-31.

[46] A. Zolfaghari, B. E. Conway, G. Jerkiewicz, Electrochim. Acta 2002, 47, 1173-1187.

[47] N. Li, J. Lipkowski, J. Electroanal. Chem. 2000, 491, 95-102.

[48] G. A. Attard, A. Brew, K. Hunter, J. Sharman, E. Wright, Phys. Chem. Chem. Phys. 2014, 16, 13689-13698.

[49] N. Garcia-Araez, V. Climent, E. Herrero, J. Feliu, J. Lipkowski, J. Electroanal. Chem. 2005, 576, $33-41$.

[50] R. Atkin, S. Z. El Abedin, R. Hayes, L. H. S. Gasparotto, N. Borisenko, F. Endres, J. Phys. Chem. C 2009, 113, 13266-13272.
[51] M. Gnahm, D. M. Kolb, J. Electroanal. Chem. 2011, 651, 250252.

[52] T. Pajkossy, C. Müller, T. Jacob, Phys. Chem. Chem. Phys. 2018, $20,21241-21250$

[53] W. Schlindwein, A. Kavvada, R. Latham, R. Linford, Polym. Int. 2000, 49, 953-959.

[54] N. G. Tsierkezos, J. Solution Chem. 2007, 36, 289-302.

[55] C. Kvarnström, H. Neugebauer, S. Blomquist, H. J. Ahonen, J. Kankare, A. Ivaska, Electrochim. Acta 1999, 44, 2739-2750.

[56] Y. Wang, E. I. Rogers, R. G. Compton, J. Electroanal. Chem. 2010, 648, 15-19.

Manuscript received: April 30, 2021

Revised manuscript received: August 18, 2021

Accepted manuscript online: August 23, 2021

Version of record online: 


\section{Research Articles}

\section{Electrodes}

F. M. Schuett, S. J. Zeller, M. J. Eckl, F. M. Matzik, M.-K. Heubach, T. Geng, J. M. Hermann, M. Uhl, L. A. Kibler,**

A. K. Engstfeld,*

T. Jacob* |III-IIII

Versatile 3D-Printed Micro-Reference Electrodes for Aqueous and NonAqueous Solutions

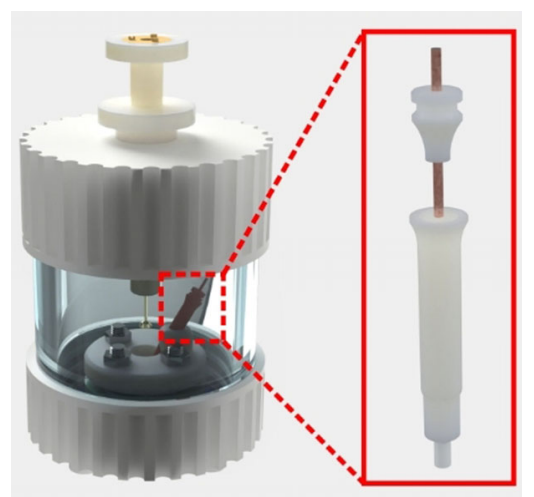

The lack of stable reference electrodes (REs) for electrochemical measurements in small cell arrangements is an oftenneglected problem. Herein we present an easily applicable procedure for the assembly of stable and cheap micro-REs, which are highly adaptable due to 3Dprinted housings; 3 aqueous and 3 nonaqueous micro-REs based on $\mathrm{Ag}, \mathrm{Cu}, \mathrm{Zn}$, and $\mathrm{Na}$. After fabrication, their stability and leak-tightness are shown by electrochemical measurements. 